\title{
Behavioral Immune System Methods: Surveying the Present to Shape the Future
}

\author{
Joshua M. Tybur \\ VU University Amsterdam
}

\author{
Willem E. Frankenhuis \\ Radboud University Nijmegen
}

\author{
Thomas V. Pollet \\ VU University Amsterdam
}

\begin{abstract}
In the short history of behavioral immune system (BIS) research, scholars have developed a number of empirical strategies for testing BIS hypotheses. These strategies have led to a wide variety of methods for testing (putatively) similar BIS hypotheses. The current article provides an overview of the 3 most frequent methods used in BIS research: cross-population correlations, experimental priming, and surveying individual differences. We first review and question the fundamental assumptions underlying each method. Then, we question the degree to which these methods can be used to test the same hypotheses. Finally, we use these methodological considerations to propose directions for future, theory-driven research on the BIS.
\end{abstract}

Keywords: disgust, behavioral immune system, cross-cultural research, priming, individual differences

Recent behavioral immune system (BIS) hypotheses have been tested using a variety of methods. In the current article, we provide an overview of these methods, and we describe their underlying assumptions, how they differ, and which research questions they have been applied to. In doing so, we pose critical questions, and we offer suggestions for future BIS research.

\section{Current BIS Methods}

To guide our decision of which methods to discuss, we first used Google Scholar to survey recent articles testing BIS hypotheses. We examined empirical articles that both (a) cited Schaller and Duncan (2007) or Schaller and Park (2011) _ two widely cited papers introducing the concept of

Joshua M. Tybur, Department of Social and Organizational Psychology, VU University Amsterdam; Willem E. Frankenhuis, Department of Developmental Psychology, Behavioural Science Institute, Radboud University Nijmegen; Thomas V. Pollet, Department of Social and Organizational Psychology, VU University Amsterdam.

Correspondence concerning this article should be addressed to Joshua M. Tybur, Department of Social and Organizational Psychology, VU University Amsterdam, Van der Boechorststraat 1, 1081 BT Amsterdam, The Netherlands. E-mail: j.m.tybur@vu.nl the BIS and (b) included the term "behavioral immune system." We observed three broad classes of methods, which we label (a) crosspopulation correlations, (b) experimental priming, and (c) individual differences. In this article, we briefly describe each class of method, and we raise questions regarding how each method has been applied to test BIS hypotheses.

\section{Method I: Cross-Population Correlations}

\section{Description of Methods}

Cross-population approaches to testing BIS hypotheses examine the degree to which (aggregated) estimates of pathogen stress in populations (e.g., nations, U.S. states) covary with (aggregated) estimates of putative pathogenneutralizing behaviors in those populations. ${ }^{1}$

\footnotetext{
${ }^{1}$ We note that some of the cross-population correlation studies we mention here are not explicitly referenced by authors as BIS studies, and, indeed, emphasize cultural evolutionary mechanisms rather than individual-level psychological adaptations for avoiding contact with pathogens (e.g., Schaller \& Murray, 2008). Nevertheless, several studies using these methods are referred to by their authors as testing BIS hypotheses (e.g., van Leeuwen, Park, Koenig, \& Graham, 2012; White et al., 2013), and BIS studies using experimental priming or individual-differences methods often cite crosspopulation studies as offering convergent evidence.
} 
Studies of cross-population correlations assume either that (a) antipathogen psychological mechanisms are facultatively activated more in pathogen-rich relative to pathogen-poor ecologies, (b) pathogen exposure during development engenders pathogen-neutralizing personality types (e.g., collectivistic orientations; lower openness to experience), or (c) pathogen-rich ecologies favor the evolution of pathogenneutralizing cultural variants (e.g., antimicrobial spices in cuisine; Billing \& Sherman, 1998). A variety of methods have been used to index pathogen stress within ecologies. Some studies have followed Low's (1990) method of first identifying a groups of parasites (e.g., schistosomes), then assigning an ordinal score (e.g., 1, 2, or 3) for each parasite based on its presence in a nation, and then summing these ordinal scores across a number of parasite groups (e.g., Fincher \& Thornhill, 2008; Schaller \& Murray, 2008). This sum is interpreted as an index of pathogen stress for a population. Others have assigned dichotomous present-absent values to infectious diseases and computed sum scores for each population (e.g., Thornhill, Fincher, Murray, \& Schaller, 2010), or have used World Health Organization or Center for Disease Control estimates of morbidity and mortality caused by infectious disease (e.g., Fincher \& Thornhill, 2012). Finally, some studies have used more general indices of health, including infant mortality rate and overall life expectancy, as proxies for parasite stress (e.g., DeBruine, Jones, Crawford, Welling, \& Little, 2010a; White, Kenrick, \& Neuberg, 2013). Cross-population methods have been used to examine how the BIS might relate to a number of variables, including indices of government or economic functioning (Murray, Schaller, \& Suedfeld, 2013; Thornhill, Fincher, \& Aran, 2009), scientific and technological innovation (Murray, 2014), religiosity or number of religious institutions (Fincher \& Thornhill, 2008, 2012), intrastate conflict (Letendre, Fincher, \& Thornhill, 2010), personality (Schaller \& Murray, 2008; Thornhill et al., 2010), and preferences for attractiveness or sexual dimorphism in faces (DeBruine et al., 2010a; Gangestad \& Buss, 1993; Gangestad, Haselton, \& Buss, 2006; White et al., 2013).

\section{Question 1: Can Inferences Based on Cross-Population Observations Inform Individual-Level Processes?}

Patterns observed at one level of analysis are often poor predictors of patterns at another level of analysis. Indeed, using group-level data to make inferences about individual-level relationships has been common enough-and frequently misleading enough - to be referred to with a specific term: the Ecological Fallacy. We list a few examples. In the early 20th century, U.S. states with higher immigrant populations had higher literacy rates, but individual immigrants were less likely to be literate than nonimmigrants (Robinson, 1950). In the early $21 \mathrm{st}$ century, U.S. states with higher mean individual incomes were more likely to vote Democrat, but wealthier individuals within states (especially Republican-leaning states) were more likely to vote Republican (Gelman, Shor, Bafumi, \& Park, 2007). Countries with higher mean chocolate consumption have more Nobel Prize winners, but no evidence (yet) demonstrates that individuals who consume more chocolate are more likely to win Nobel Prizes or have any advantage in cognitive functioning (Maurage, Heeren, \& Pesenti, 2013; Messerli, 2012). These types of inconsistencies are not just idiosyncratic or counterintuitive. Instead, they are indicative of a general problem with generalizing from one level of analysis to another (for recent relevant discussions, see Hruschka \& Hackman, 2014; Kievit, Frankenhuis, Waldorp, \& Borsboom, 2013; Pollet, Tybur, Frankenhuis, \& Rickard, in press). Hence, BIS interpretations of consistencies-or inconsistencies-between results gleaned from cross-population versus individuallevel analyses should be treated with caution.

\section{Question 2: What Are the Validities of Cross-Population Operationalizations of Pathogen Stress?}

As summarized thus far, researchers have used a variety of methods to estimate population-level pathogen stress. The validity of these estimates as measuring pathogen concentration in a population has not always been clear. For example, Hackman and Hruschka (2013a) have argued that Fincher and Thornhill's (2012) pathogen stress index-which was computed 
for each U.S. state using Centers for Disease Control estimates of morbidity and mortality caused by infectious disease-largely measures infections that are transmitted primarily via sexual contact (e.g., chlamydia). Hackman and Hruschka (2013a, 2013b) and Thornhill and Fincher (2013) have debated the degree to which this variable's status as an index of specifically sexually transmitted infections versus an index of more general pathogen-richness influences its validity for testing BIS hypotheses. Regardless of the outcome of this specific debate, the conversation underscores the possibility that seemingly straightforward estimates of pathogen stress typically combine different types of pathogens, which might use different routes of transmission, and are consequently mitigated by different behavioral strategies, and, perhaps most importantly, are differentially confounded with other variables (e.g., as Hackman and Hruschka argue, ethnicity). The point also applies - perhaps more strongly - to methods that operationalize pathogen threats with proxies that are posited as outcomes of pathogen infection (e.g., life expectancy, infant mortality; DeBruine et al., 2010a; White et al., 2013) rather than direct estimates of pathogen richness.

\section{Method II: Experimental Priming}

\section{Description of Methods}

A second popular method in BIS research involves first exposing participants to cues to pathogens and then measuring participants' attitudes or behavior. Often couched within the fundamental motives framework (Kenrick, Griskevicius, Neuberg, \& Schalle, 2010), this method assumes that the computational mechanisms underlying the BIS take cues to pathogens as input, process this information, and output pathogen-neutralizing behaviors as a "goal" that is temporarily prioritized relative to the period before cues to pathogens were detected (cf. Tybur, Lieberman, Kurzban, \& DeScioli, 2013). Multiple methods of activating such goal states have been used, including exposing participants to olfactory cues to pathogens (e.g., Tybur, Bryan, Magnan, \& Caldwell Hooper, 2011), visual cues to pathogens (e.g., Schaller, Miller, Gervais, Yager, \& Chen, 2010; Stevenson, Hodgson, Oaten, Barouei, \& Case,
2011), or visual cues juxtaposed with verbal information regarding infectious disease threats (e.g., Ackerman et al., 2009; Mortensen, Becker, Ackerman, Neuberg, \& Kenrick, 2010), or having participants read vignettes describing contact with pathogenic substances (e.g., mucus from sneezes; White et al., 2013) or complete individual-differences measures, such as the Perceived Vulnerability to Disease (PVD) scale (Lee \& Zietsch, 2011; Watkins, DeBruine, Little, Feinberg, \& Jones, 2012). Studies using these methods suggest that exposure to pathogen cues leads to increased attention toward disfigured faces (Ackerman et al., 2009), increased physical attraction to sexual dimorphism and symmetry in opposite sex faces (Little, DeBruine, \& Jones, 2011), increased preferences for physically attractive political candidates (White et al., 2013), increased intentions to use condoms in future sexual interactions (Tybur et al., 2011), and increased prejudicial attitudes toward groups hypothesized to be heuristically associated with infectious disease (e.g., immigrants, gay men, obese people; see Faulkner, Schaller, Park, \& Duncan, 2004; Inbar, Pizarro, \& Bloom, 2012, and Park, Schaller, \& Crandall, 2007, respectively).

\section{Question 3: Do the Goal States Activated by Different Pathogen Cues Differ?}

Although a variety of stimulus types have been used interchangeably to activate a pathogen-avoidance goal state, the mechanisms undergirding the BIS need not process all cues to pathogens in the same manner and yield the same outputs (e.g., changes in attention, memory, attitudes, preferences). For example, tactile cues to pathogens (e.g., touching something wet and viscous with your hand; Oum, Lieberman, \& Aylward, 2011) presumably leads to a stronger "pull away" response than, say, olfactory cues to pathogens. The precise coupling between different types of pathogen cues and their effects on attention, memory, and other systems is not yet clear. Some BIS research has demonstrated that attention to, and memory for, specific types of faces (e.g., disfigured ones) changes after exposure to visual cues to pathogens. Olfactory cues to pathogens could lead to visual search for the source of the odor and, potentially, attention to, and memory for, stimuli in the ecology in a different manner relative 
to visual cues to pathogens. Moreover, even within the same modality, different kinds of cues might have distinct effects on attention and memory. Alternatively, the felt output of the mechanisms underlying pathogen disgustregardless of the cues that led to the disgustcould act as an input into attention and memory systems, such that disgust across stimulus types could have the same effects on cognition (cf. Schaller, 2014; Tybur et al., 2013). The type of BIS designs (general response vs. distinct responses) that natural selection favors could depend on ecology (e.g., the precision with which cues indicate pathogens; spatial and temporal fluctuations in pathogen levels), the state of the organism (e.g., energetic costs of producing general vs. specific responses; the costs of mounting an incorrect specific response), the life stage of the organism (e.g., selection is stronger earlier in life), and other factors. Dynamic optimization models offer a promising tool for understanding such state-dependent tradeoffs (Frankenhuis, Panchanathan, \& Barrett, 2013).

\section{Question 4: How Should We Interpret Moderated Effects of Experimental Priming?}

Experimental priming procedures sometimes have main effects on dependent measures (e.g., Ackerman et al., 2009; Tybur et al., 2011), and they sometimes interact with individualdifferences variables, whereby which the prime has the predicted effect only for individuals with relatively high within-sample BIS activation (e.g., Mortensen et al., 2010; Park, Faulkner, \& Schaller, 2003). It is unclear why some studies find interactions and others find only main effects. It is possible that individuals high in trait-level BIS activation are more sensitive to detecting pathogen cues, and are thus more likely to detect experimental manipulations (inputs). Alternatively, individual differences might not depend on detection of experimentally manipulated cues, but they might influence the degree to which participants invest in pathogen-avoidant behaviors in response to these cues (outputs). Finally, it is possible that inconsistencies in main effects versus interactions across studies result either from designs that are underpowered for detecting interactions or from Type I errors in tests of interactions.

\section{Method III: Individual-Differences Measures}

\section{Description of Methods}

The third method we identified examines how individual-level scores on self-report instruments posited to reflect trait-level BIS activation covary with other individual-level measures (e.g., personality) or moderate the effects of experimental primes (e.g., Mortensen et al., 2010). The three most popular (cf. Terrizzi, Shook, \& McDaniel, 2013) instruments include (a) the PVD scale (Duncan, Schaller, \& Park, 2009), (b) the Disgust Scale (DS; Haidt, McCauley, \& Rozin, 1994), and (c) the ThreeDomain Disgust Scale (TDDS; Tybur, Lieberman, \& Griskevicius, 2009). We briefly describe each of these instruments.

PVD scale. Park et al. (2003, 2007) and Faulkner et al. (2004) describe preliminary versions of the PVD scale in studies examining prejudice toward physically handicapped individuals and immigrants, respectively. Duncan et al. (2009) later described the validation of a 15 -item version of the scale and suggested that it is composed of two factors, which are labeled Germ Aversion and Perceived Infectability. The Germ Aversion factor aligns closely with what is referred to as the "contamination sensitivity" facet of obsession and compulsion instruments. For example, the germ-aversion item "My hands do not feel dirty after touching money" corresponds closely with the Vancouver Obsessive Compulsive Inventory (Thordarson et al., 2004) item "I feel very dirty after touching money" and the Padua Inventory item "I feel my hands are dirty when I touch money" (Sanavio, 1988). In contrast, the Perceived Infectability factor includes items referencing frequency of illness (e.g., "If an illness is 'going around,' I will get it"). Despite demonstrating different validity and being only modestly correlated ( $r=.30$, as reported by Duncan et al.), the two factors have sometimes been averaged to estimate a single PVD construct in the BIS literature (e.g., Miller \& Maner, 2012; Mortensen et al., 2010; Tybur et al., 2009), though they have also been analyzed separately (e.g., Prokop, Usak, \& Fancovicová, 2010; Terrizzi, Clay, \& Shook, 2014).

DS. Haidt et al. (1994) designed the instrument by first asking 20 individuals to describe 
things that elicit disgust. After reading 221 descriptions from these 20 individuals, the authors concluded that responses reflected eight qualitatively different domains. The authors then constructed a 32-item instrument designed to measure seven of these eight domains, plus an additional domain they labeled "magic" (the authors did not retain the "moral" domain that they observed in the item-generation process because responses to these items did not covary strongly with responses to the other items). Several versions of the DS have been used in the literature, including the original instrument, revisions of the instrument that were retrieved via personal communication with Jon Haidt or from his personal web page (e.g., the "short form" DS - see Inbar, Pizarro, \& Bloom, 2009—and the "DS-2"- - see Hodson \& Costello, 2007), and the Disgust Scale-Revised (DS-R; Olatunji et al., 2007), which removed seven items from the original DS. Each version suggests different procedures by which the same (or mostly the same) items should be categorized and computed, with the original DS having eight intended subfactors, the DS short-form having a single intended factor, the DS-2 having four intended subfactors, and the DS-R having three intended subfactors. Researchers using the various versions of the DS have alternated between computing subfactor and total scores (Tybur et al., 2009).

The meaning of the construct(s) measured by the DS-and, hence, the appropriateness of the DS for testing BIS hypotheses- has not always been clear. The original scale, which some have summed to test BIS hypotheses (e.g., Fessler, Eng, \& Navarrete, 2005; Terrizzi et al., 2010), includes multiple items related to moral judgment of sexual acts (e.g., "I think it is immoral for people to seek sexual pleasure from animals"). And although the items from the sex factor of the original DS were among the seven items removed by Olatunji et al. (2007), the DS-R retains multiple quirks of the original instrument, including (a) 13 of the 25 items ask respondents to note "true" or "false" with statements that do not relate straightforwardly to pathogen avoidance or, perhaps, even to disgust (e.g., "I would go out of my way to avoid walking through a graveyard"); (b) some items measured on a scale asking for disgust responses have a questionable relationship to pathogen-avoidance (e.g., "You see someone put ketchup on vanilla ice cream, then eat it"); and (c) some of these items continue to have sexual content (e.g., "As part of a sex education class, you are required to inflate a new unlubricated condom using your mouth"; see, e.g., Inbar, Pizarro, Iyer, \& Haidt, 2012).

TDDS. The TDDS is a 21-item instrument with which participants rate how disgusting they find each scale item on a seven-point scale anchored by not at all disgusting and extremely disgusting. The scale has three factors: (a) a Pathogen factor (e.g., "Seeing some mold on old leftovers in your refrigerator"), (b) a Sexual factor (e.g., "Finding out that someone you don't like has sexual fantasies about you"), and (c) a Moral factor (e.g., "Intentionally lying during a business transaction"). The pathogen factor of the TDDS appears most valid for testing BIS hypotheses and, indeed, out of the three factors, it relates most strongly to the total DS-R (Tybur, Merriman, Caldwell, McDonald, \& Navarrete, 2010). Nevertheless, some investigations have summed across all three factors of the TDDS to test BIS hypotheses or have used the sexual or moral subscales to operationalize trait BIS activation (e.g., Pond et al., 2012; Terrizzi et al., 2014).

\section{Question 5: Are All Individual-Differences Measures Currently Used to Test BIS Hypotheses Valid Measures of the BIS?}

Multiple self-report instruments are currently used interchangeably to test BIS hypotheses. As an example, in a recent study investigating how the BIS influences religious conservatism and collectivism, Terrizzi et al. (2014) administered the PVD scale, TDDS, DS-R, and Disgust Propensity and Sensitivity Scale (van Overveld, de Jong, Peters, Cavanagh, \& Davey, 2006). Although all of these instruments were posited to measure traitlevel BIS activation, they had varied relationships with the criterion variables, with the sexual domain of the TDDS having the strongest relationships. Indeed, sensitivity to sexual disgust fully mediated sex differences in religious conservatism, and this finding was interpreted as demonstrating that men and women differ in religious conservatism because of a sex difference in BIS activation. Other recent articles have suggested that sexual content in the DS increases its validity as a measure of trait BIS activation (Terrizzi et al., 2013), and that the sexual and moral domains of 
the TDDS reflect trait BIS activation (Pond et al., 2012). We are skeptical of the validity of testing BIS hypotheses using scale items concerning watching pornography, performing oral sex, and receiving uninvited sexual advances (example items from the TDDS Sexual factor); deception and betrayal (item content from the TDDS Moral factor); or incest, homosexual sex, and inflating condoms with one's mouth (example items from the DS that include sexual content). Sexual disgust appears functionally designed to mitigate costs specifically associated with reproduction rather than with infectious disease in general (Fessler \& Navarrete, 2003; Fleischman, 2014; Tybur et al., 2009; Tybur et al., 2013). Consequently, in contrast to Terrizzi et al.'s (2014) interpretation of their data, we suggest that correlations between religious conservatism and sensitivity to sexual disgust indicate that religious conservatism is (at least partially) a reproductive strategy rather than a pathogen-avoidance strategy (cf. Kurzban, Dukes, \& Weeden, 2010; Weeden, Cohen, \& Kenrick, 2008; Weeden \& Kurzban, 2013, 2014).

\section{Question 6: What Differentiates Measures That Purport to Measure BIS Activation?}

Whereas putative differences between pathogen and sexual disgust have been explored in the literature and tested empirically, little work has examined differences between other commonly used measures of trait-level BIS activation that seem to relate more straightforwardly to pathogen-avoidance. DS-R total scores are moderately related to PVD germ aversion scores (e.g., $r=$ .55; Duncan et al., 2009), and the pathogen domain of the TDDS is moderately related to the contamination factor of Padua Inventory (e.g., $r=$ .43; Olatunji et al., 2012), which is similar to the PVD germ-aversion factor. All of these variables are only weakly related to the PVD Perceived Infectability factor ( $r$ s with the DS-R and Germ Aversion factor under .30; Duncan et al., 2009). In sum, variables that are currently used interchangeably to test BIS hypotheses seem to reflect distinct constructs. In future BIS research, rather than using these instruments interchangeably, researchers could (and, perhaps, should) explain differences in the constructs measured by these instruments and use this information to select the most valid instrument for testing a particular hypothesis.

\section{Different Methods, Different Questions}

\section{Question 7: Across Methods, How Specific Are BIS Methods to the BIS?}

Across all three classes of methods discussed in this article, researchers have attempted to demonstrate that observations are BIS specific. For example, cross-population correlation methods have attempted to control for other variables when testing for relationships between parasite stress and other variables (e.g., national wealth; see Fincher \& Thornhill, 2012), experimental priming researchers have used nonpathogenic "danger" primes as control conditions (e.g., Mortensen et al., 2010; Schaller et al., 2010), and individual-differences researchers have attempted to demonstrate that PVD and disgust sensitivity scores do not merely reflect variation in neuroticism or openness to experience (Duncan et al., 2009; Tybur \& de Vries, 2013; Tybur et al., 2009). Even with perfect measurement of the constructs targeted in these approaches, though, researchers might encounter issues that threaten the validity of inferences. The BIS has been defined as a suite of psychological mechanisms that ultimately function to "facilitate the avoidance of ... pathogens before they make contact with the body" (Schaller \& Park, 2011, p. 99). However, psychological systems with functions distinct from neutralizing physical contact with pathogens might nevertheless take cues to pathogens as input, or might covary with trait-level BIS activation. Work on mate preferences, for example, suggests that national parasite-stress levels, experimental primes, and individual-differences measures all relate to preferences for attractiveness, sexual dimorphism, symmetry, or health in mates (DeBruine et al., 2010a; DeBruine, Jones, Tybur, Lieberman, \& Griskevicius, 2010b; Gangestad et al., 2006; Jones et al., 2013; Little et al., 2011; Park, van Leeuwen, \& Stephen, 2012). These effects could indeed reflect adaptations for avoiding contact with pathogens, if such physical features in potential mates convey information about current or likely future infection state (or, at least, did so in the ancestral environment). However, even if these features do provide information regarding current or future infection, preferences might not reflect pathogen avoidance per se; rather, they could reflect increased preferences for individuals 
who will not be incapacitated by infection (which can be useful in leaders, platonic social allies, or pair-bond partners) or preferences for heritable immunity (which can provide fitnesspromoting indirect benefits from a mate, especially when pathogens impose particularly severe costs; see Tybur \& Gangestad, 2011).

The degree to which this issue threatens inferences concerning the BIS depends on the definition of the BIS. If it is defined narrowly as psychological mechanisms that motivate avoidance of contact with pathogens, then the methods that are assumed to test BIS hypotheses might test different, non-BIS hypotheses. If the BIS is defined more broadly as all psychological mechanisms that take pathogen cues as input- or output which motivates behaviors mitigating against threats posed by pathogens, either direct or indirect-then all methods discussed here might test BIS hypotheses (cf. Thornhill \& Fincher, 2014). If the latter, however, the "immune" part of the BIS becomes a bit of a misnomer. One of the strengths of BIS research has been to highlight how important considerations of pathogens are for understanding human psychology and behavior (cf. Thomas, Daoust, \& Raymond, 2012); ultimately, one agenda for BIS researchers might be to map aspects of our psychology that function to neutralize pathogens, but which are not part of the BIS, as currently defined.

\section{Concluding Remarks}

As in any maturing field of inquiry, it is valuable to occasionally survey the field and take stock of the current state of the art. Based on such an appraisal, we see that BIS research has yielded an impressive array of theoretical proposals and empirical results in a very short amount of time. This volume of ideas and data, while informative in many ways, has also raised new questions regarding how we should interpret existing findings regarding the function, the development, and the information-processing structures of the BIS. In this overview, we have raised some questions that challenge methodological and theoretical assumptions common in the BIS literature. Our hope is that these questions will spur new investigations that can simultaneously elucidate the validity of research methods and our scientific understanding of the BIS. We fully anticipate that new theo- retical insights and empirical discoveries will continue to emerge in the coming years, and we hope that our critical eye toward the validity of currently popular methods can contribute to this enterprise.

\section{References}

Ackerman, J. M., Becker, D. V., Mortensen, C. R., Sasaki, T., Neuberg, S. L., \& Kenrick, D. T. (2009). A pox on the mind: Disjunction of attention and memory in the processing of physical disfigurement. Journal of Experimental Social Psychology, 45, 478-485. doi:10.1016/j.jesp.2008 .12 .008

Billing, J., \& Sherman, P. W. (1998). Antimicrobial functions of spices: Why some like it hot. Quarterly Review of Biology, 73, 3-49. doi:10.1086/ 420058

DeBruine, L. M., Jones, B. C., Crawford, J. R., Welling, L. L., \& Little, A. C. (2010a). The health of a nation predicts their mate preferences: Crosscultural variation in women's preferences for masculinized male faces. Proceedings of the Royal Society of London: Series B: Biological Sciences, 277, 2405-2410. doi:10.1098/rspb.2009.2184

DeBruine, L. M., Jones, B. C., Tybur, J. M., Lieberman, D., \& Griskevicius, V. (2010b). Women's preferences for masculinity in male faces are predicted by pathogen disgust, but not by moral or sexual disgust. Evolution and Human Behavior, 31, 69-74. doi:10.1016/j .evolhumbehav.2009.09.003

Duncan, L. A., Schaller, M., \& Park, J. H. (2009). Perceived vulnerability to disease: Development and validation of a 15-item self-report instrument. Personality and Individual Differences, 47, 541-546.

Faulkner, J., Schaller, M., Park, J. H., \& Duncan, L. A. (2004). Evolved disease-avoidance processes and contemporary xenophobic attitudes. Group Processes \& Intergroup Relations, 7, 333-353. doi:10.1177/1368430204046142

Fessler, D. M. T., Eng, S. J., \& Navarrete, C. D. (2005). Disgust sensitivity is elevated in the first trimester of pregnancy: Evidence supporting the compensatory prophylaxis hypothesis. Evolution and Human Behavior, 26, 344-351. doi:10.1016/ j.evolhumbehav.2004.12.001

Fessler, D. M. T., \& Navarrete, C. D. (2003). Domain-specific variation in disgust sensitivity across the menstrual cycle. Evolution and Human Behavior, 24, 406-417. doi:10.1016/S1090-5138(03) 00054-0

Fincher, C. L., \& Thornhill, R. (2008). Assortative sociality, limited dispersal, infectious disease and the genesis of the global pattern of religion diversity. Proceedings of the Royal Society of London: 
Series B: Biological Sciences, 275, 2587-2594. doi:10.1098/rspb.2008.0688

Fincher, C. L., \& Thornhill, R. (2012). Parasite-stress promotes in-group assortative sociality: The cases of strong family ties and heightened religiosity. Behavioral and Brain Sciences, 35, 61-79. doi: 10.1017/S0140525X11000021

Fleischman, D. S. (2014). Women's disgust adaptations. In V. A. Weekes-Shackelford \& T. K. Shackelford (Eds.), Evolutionary perspectives on human sexual psychology and behavior (pp. 277296). New York, NY: Springer. doi:10.1007/9781-4939-0314-6_15

Frankenhuis, W. E., Panchanathan, K., \& Barrett, H. C. (2013). Bridging developmental systems theory and evolutionary psychology using dynamic optimization. Developmental Science, 16, 584598. doi:10.1111/desc.12053

Gangestad, S. W., \& Buss, D. M. (1993). Pathogen prevalence and human mate preferences. Ethology and sociobiology, 14, 89-96. doi:10.1016/01623095(93)90009-7

Gangestad, S. W., Haselton, M. G., \& Buss, D. M. (2006). Evolutionary foundations of cultural variation: Evoked culture and mate preferences. Psychological Inquiry, 17, 75-95. doi:10.1207/ s15327965pli1702_1

Gelman, A., Shor, B., Bafumi, J., \& Park, D. (2007). Rich state, poor state, red state, blue state: What's the matter with Connecticut? Quarterly Journal of Political Science, 2, 345-367. doi:10.1561/100 .00006026

Hackman, J., \& Hruschka, D. (2013a). Fast life histories, not pathogens, account for state-level variation in homicide, child maltreatment, and family ties in the U.S. Evolution and Human Behavior, 34, 118-124. doi:10.1016/j.evolhumbehav.2012 .11 .002

Hackman, J., \& Hruschka, D. (2013b). Commentary on Hackman, J., \& Hruschka, D. (2013). Fast life histories, not pathogens, account for state-level variation in homicide, child maltreatment, and family ties in the US, Evolution and Human Behavior, 34,118-124 Response. Evolution and $\mathrm{Hu}$ man Behavior, 34, 315-316. doi:10.1016/j.evolhumbehav.2013.04.005

Haidt, J., McCauley, C., \& Rozin, P. (1994). Individual-differences in sensitivity to disgust: A scale sampling seven domains of disgust elicitors. Personality and Individual Differences, 16, 701-713. doi:10.1016/0191-8869(94)90212-7

Hodson, G., \& Costello, K. (2007). Interpersonal disgust, ideological orientations, and dehumanization as predictors of intergroup attitudes. Psychological Science, 18, 691-698. doi:10.1111/j.14679280.2007.01962.x

Hruschka, D. J., \& Hackman, J. (2014). When are cross-group differences a product of a human be- havioral immune system? Evolutionary Behavioral Sciences, 8, 265-273.

Inbar, Y., Pizarro, D. A., \& Bloom, P. (2009). Conservatives are more easily disgusted than liberals. Cognition and Emotion, 23, 714-725. doi: 10.1080/02699930802110007

Inbar, Y., Pizarro, D. A., \& Bloom, P. (2012). Disgusting smells cause decreased liking of gay men. Emotion, 12, 23-27. doi:10.1037/a0023984

Inbar, Y., Pizarro, D., Iyer, R., \& Haidt, J. (2012). Disgust sensitivity, political conservatism, and voting. Social Psychological \& Personality Science, 3, 537-544. doi:10.1177/1948550611429024

Jones, B. C., Feinberg, D. R., Watkins, C. D., Fincher, C. L., Little, A. C., \& DeBruine, L. M. (2013). Pathogen disgust predicts women's preferences for masculinity in men's voices, faces, and bodies. Behavioral Ecology, 24, 373-379. doi: 10.1093/beheco/ars173

Kenrick, D. T., Griskevicius, V., Neuberg, S. L., \& Schaller, M. (2010). Renovating the pyramid of needs: Contemporary extensions built upon ancient foundations. Perspectives on Psychological Science, 5, 292314. doi:10.1177/1745691610369469

Kievit, R. A., Frankenhuis, W. E., Waldorp, L. J., \& Borsboom, D. (2013). Simpson's paradox in psychological science: A practical guide. Frontiers in Psychology, 4, 513. doi:10.3389/fpsyg.2013.00513

Kurzban, R., Dukes, A., \& Weeden, J. (2010). Sex, drugs, and moral goals: Reproductive strategies and views about recreational drugs. Proceedings of the Royal Society of London: Series B: Biological Sciences, 277, 3501-3508. doi:10.1098/rspb.2010 .0608

Lee, A. J., \& Zietsch, B. P. (2011). Experimental evidence that women's mate preferences are directly influenced by cues of pathogen prevalence and resource scarcity. Biology Letters, 7, 892-895. doi:10.1098/rsbl.2011.0454

Letendre, K., Fincher, C. L., \& Thornhill, R. (2010). Does infectious disease cause global variation in the frequency of intrastate armed conflict and civil war? Biological Reviews, 85, 669-683.

Little, A. C., DeBruine, L. M., \& Jones, B. C. (2011). Exposure to visual cues of pathogen contagion changes preferences for masculinity and symmetry in opposite-sex faces. Proceedings of the Royal Society of London: Series B: Biological Sciences, 278, 2032-2039. doi:10.1098/rspb.2010.1925

Low, B. S. (1990). Marriage systems and pathogen stress in human societies. American Zoologist, 30, 325-339.

Maurage, P., Heeren, A., \& Pesenti, M. (2013). Does chocolate consumption really boost Nobel award chances? The peril of over-interpreting correlations in health studies. The Journal of Nutrition, 143, 931-933. doi:10.3945/jn.113.174813 
Messerli, F. H. (2012). Chocolate consumption, cognitive function, and Nobel laureates. The New England Journal of Medicine, 367, 1562-1564. doi: 10.1056/NEJMon 1211064

Miller, S. L., \& Maner, J. K. (2012). Overperceiving disease cues: The basic cognition of the behavioral immune system. Journal of Personality and Social Psychology, 102, 1198-1213. doi:10.1037/ a0027198

Mortensen, C. R., Becker, D. V., Ackerman, J. M., Neuberg, S. L., \& Kenrick, D. T. (2010). Infection breeds reticence: The effects of disease salience on self-perceptions of personality and behavioral tendencies. Psychological Science, 21, 440-447. doi: 10.1177/0956797610361706

Murray, D. R. (2014). Direct and indirect implications of disease threat for scientific and technological innovation. Journal of Cross-Cultural Psychology, 45, 971-985. doi:10.1177/00220221 14532356

Murray, D. R., Schaller, M., \& Suedfeld, P. (2013). Pathogens and politics: Further evidence that parasite prevalence predicts authoritarianism. PLOS One, 8, e62275. doi:10.1371/journal.pone .0062275

Olatunji, B. O., Adams, T., Ciesielski, B., David, B., Sarawgi, S., \& Broman-Fulks, J. (2012). The Three Domains of Disgust Scale: Factor structure, psychometric properties, and conceptual limitations. Assessment, 19, 205-225. doi:10.1177/ 1073191111432881

Olatunji, B. O., Williams, N. L., Tolin, D. F., Sawchuk, C. N., Abramowitz, J. S., Lohr, J. M., \& Elwood, L. (2007). The Disgust Scale: Item analysis, factor structure, and suggestions for refinement. Psychological Assessment, 19, 281-297. doi:10.1037/1040-3590.19.3.281

Oum, R. E., Lieberman, D., \& Aylward, A. (2011). A feel for disgust: Tactile cues to pathogen presence. Cognition \& Emotion, 25, 717-725. doi:10.1080/ 02699931.2010.496997

Park, J. H., Faulkner, J., \& Schaller, M. (2003). Evolved disease-avoidance processes and contemporary anti-social behavior: Prejudicial attitudes and avoidance of people with physical disabilities. Journal of Nonverbal Behavior, 27, 65-87. doi: 10.1023/A:1023910408854

Park, J. H., Schaller, M., \& Crandall, C. S. (2007). Pathogen-avoidance mechanisms and the stigmatization of obese people. Evolution and Human Behavior, 28, 410-414. doi:10.1016/j.evolhumbehav .2007 .05 .008

Park, J. H., van Leeuwen, F., \& Stephen, I. D. (2012). Homeliness is in the disgust sensitivity of the beholder: Relatively unattractive faces appear especially unattractive to individuals higher in pathogen disgust. Evolution and Human Behavior, 33, 569-577. doi:10.1016/j .evolhumbehav.2012.02.005
Pollet, T. V., Tybur, J. M., Frankenhuis, W. E., \& Rickard, I. J. (in press). What can cross-cultural correlations teach us about human nature? Human Nature.

Pond, R. S., DeWall, C. N., Lambert, N. M., Deckman, T., Bonser, I. M., \& Fincham, F. D. (2012). Repulsed by violence: Disgust sensitivity buffers trait, behavioral, and daily aggression. Journal of Personality and Social Psychology, 102, 175-188. doi:10.1037/a0024296

Prokop, P., Usak, M., \& Fancovicová, J. (2010). Risk of parasite transmission influences perceived vulnerability to disease and perceived danger of disease-relevant animals. Behavioural Processes, 85, 52-57. doi:10.1016/j.beproc.2010.06.006

Robinson, W. S. (1950). Ecological correlations and the behavior of individuals. American Sociological Review, 15, 351-357. doi:10.2307/2087176

Sanavio, E. (1988). Obsessions and compulsions: The Padua Inventory. Behaviour Research and Therapy, 26, 169-177. doi:10.1016/0005-7967 (88)90116-7

Schaller, M. (2014). When and how disgust is and isn't implicated in the behavioral immune system. Evolutionary Behavioral Sciences.

Schaller, M., \& Duncan, L. A. (2007). The behavioral immune system: Its evolution and social psychological implications. In J. P. Forgas, M. G. Haselton, \& W. von Hippel (Eds.), Evolution and the social mind: Evolutionary psychology and social cognition (pp. 293-307). New York, NY: Psychology Press.

Schaller, M., Miller, G. E., Gervais, W. M., Yager, S., \& Chen, E. (2010). Mere visual perception of other people's disease symptoms facilitates a more aggressive immune response. Psychological Science, 21, 649-652. doi:10.1177/0956797 610368064

Schaller, M., \& Murray, D. R. (2008). Pathogens, personality and culture: Disease prevalence predicts worldwide variability in sociosexuality, extraversion, and openness to experience. Journal of Personality and Social Psychology, 95, 212-221. doi:10.1037/0022-3514.95.1.212

Schaller, M., \& Park, J. H. (2011). The behavioral immune system (and why it matters). Current Directions in Psychological Science, 20, 99-103. doi:10.1177/0963721411402596

Stevenson, R. J., Hodgson, D., Oaten, M. J., Barouei, J., \& Case, T. I. (2011). The effect of disgust on oral immune function. Psychophysiology, 48, 900-907. doi:10.1111/j.1469-8986.2010.01165.x

Terrizzi, J. A., Jr., Clay, R., \& Shook, N. J. (2014). Does the behavioral immune system prepare females to be religiously conservative and collectivistic? Personality and Social Psychology Bulletin, 40, 189-202. doi:10.1177/0146167213508792 
Terrizzi, J. A., Jr., Shook, N. J., \& McDaniel, M. A. (2013). The behavioral immune system and social conservatism: A meta-analysis. Evolution and Human Behavior, 34, 99-108. doi: 10.1016/j.evolhumbehav.2012.10.003

Terrizzi, J. A., Jr., Shook, N. J., \& Ventis, W. L. (2010). Disgust: A predictor of social conservatism and prejudicial attitudes toward homosexuals. Personality and Individual Differences, 49, 587592. doi:10.1016/j.paid.2010.05.024

Thomas, F., Daoust, S. P., \& Raymond, M. (2012). Can we understand modern humans without considering pathogens? Evolutionary Applications, 5, 368-379. doi:10.1111/j.1752-4571.2011.00231.x

Thordarson, D. S., Radomsky, A. S., Rachman, S., Shafran, R., Sawchuk, C. N., \& Ralph Hakstian, A. (2004). The Vancouver Obsessional Compulsive Inventory (VOCI). Behaviour Research and Therapy, 42, 1289-1314. doi:10.1016/j.brat.2003.08.007

Thornhill, R., \& Fincher, C. L. (2013). Commentary on Hackman, J., \& Hruschka, D. (2013). Fast life histories, not pathogens, account for state-level variation in homicide, child maltreatment, and family ties in the US Evolution and Human Behavior, 34,118-124. Evolution and Human Behavior, 34, 314-315. doi:10.1016/j.evolhumbehav .2013.03.006

Thornhill, R., \& Fincher, C. L. (2014). The parasitestress theory of sociality, the behavioral immune system, and human social and cognitive uniqueness. Evolutionary Behavioral Sciences.

Thornhill, R., Fincher, C. L., \& Aran, D. (2009). Parasites, democratization, and the liberalization of values across contemporary countries. Biological Reviews, 84, 113-131. doi:10.1111/j.1469185X.2008.00062.x

Thornhill, R., Fincher, C. L., Murray, D. R., \& Schaller, M. (2010). Zoonotic and nonzoonotic diseases in relation to human personality and societal values: Support for the parasite stress model. Evolutionary Psychology, 8, 151-169.

Tybur, J. M., Bryan, A. D., Magnan, R. E., \& Caldwell Hooper, A. E. (2011). Smells like safe sex: Olfactory pathogen primes increase intentions to use condoms. Psychological Science, 22, 478480. doi:10.1177/0956797611400096

Tybur, J. M., \& de Vries, R. E. (2013). Disgust sensitivity and the HEXACO model of personality. Personality and Individual Differences, 55, 660665. doi:10.1016/j.paid.2013.05.008

Tybur, J. M., \& Gangestad, S. W. (2011). Mate preferences and infectious disease: Theoretical considerations and evidence in humans. Philosophical Transactions of the Royal Society of London: Series B: Biological Sciences, 366, 33753388. doi:10.1098/rstb.2011.0136
Tybur, J. M., Lieberman, D., \& Griskevicius, V. (2009). Microbes, mating, and morality: Individual differences in three functional domains of disgust. Journal of Personality and Social Psychology, 97, 103-122. doi:10.1037/a0015474

Tybur, J. M., Lieberman, D., Kurzban, R., \& DeScioli, P. (2013). Disgust: Evolved function and structure. Psychological Review, 120, 65-84. doi: 10.1037/a0030778

Tybur, J. M., Merriman, L. A., Caldwell, A. E., McDonald, M. M., \& Navarrete, C. D. (2010). Extending the behavioral immune system to political psychology: Are political conservatism and disgust sensitivity really related? Evolutionary Psychology, 8, 599-616.

van Leeuwen, F., Park, J. H., Koenig, B. L., \& Graham, J. (2012). Regional variation in pathogen prevalence predicts endorsement of group-focused moral concerns. Evolution and Human Behavior, 33, 429-437. doi:10.1016/j.evolhumbehav.2011 .12 .005

van Overveld, W. J. M., de Jong, P. J., Peters, M. L., Cavanagh, K., \& Davey, G. C. L. (2006). Disgust propensity and disgust sensitivity: Separate constructs that are differentially related to specific fears. Personality and Individual Differences, 41, 1241-1252. doi:10.1016/j.paid.2006.04.021

Watkins, C. D., DeBruine, L. M., Little, A. C., Feinberg, D. R., \& Jones, B. C. (2012). Priming concerns about pathogen threat versus resource scarcity: Dissociable effects on women's perceptions of men's attractiveness and dominance. Behavioral Ecology and Sociobiology, 66, 1549-1556. doi:10.1007/s00265-012-1408-2

Weeden, J., Cohen, A. B., \& Kenrick, D. T. (2008). Religious attendance as reproductive support. Evolution and Human Behavior, 29, 327-334. doi: 10.1016/j.evolhumbehav.2008.03.004

Weeden, J., \& Kurzban, R. (2013). What predicts religiosity? A multinational analysis of reproductive and cooperative morals. Evolution and Human Behavior, 34, 440-445. doi:10.1016/j.evolhumbehav.2013.08.006

Weeden, J., \& Kurzban, R. (2014). The hidden agenda of the political mind: How self-interest shapes our opinions and why we won't admit it. Princeton, NJ: Princeton University Press.

White, A. E., Kenrick, D. T., \& Neuberg, S. L. (2013). Beauty at the ballot box: Disease threats predict preferences for physically attractive leaders. Psychological Science, 24, 2429-2436. doi: $10.1177 / 0956797613493642$

Received March 28, 2014

Revision received June 17, 2014

Accepted June 20, 2014 